\title{
Effects of single, short term exposures of human retinal pigment epithelial cells to thiotepa or 5-fluorouracil: implications for the treatment of proliferative vitreoretinopathy
}

Chee Hing Kon, Nicholas Laurence Occleston, Alexander Foss, Carl Sheridan, George William Aylward, Peng Tee Khaw

\begin{abstract}
Aim-To investigate the effects of single, short term ( 5 or 30 minutes) exposures to thiotepa or 5-fluorouracil (5-FU) on collagen lattice contraction and retinal pigment epithelial (RPE) cell proliferation. Methods-For collagen contraction studies, RPE cells seeded into free floating type I collagen lattices were exposed to single 5 or 30 minute treatments with thiotepa $(0.06-4 \mathrm{mg} / \mathrm{ml})$, or $5-\mathrm{FU}(0.25-25$ $\mathrm{mg} / \mathrm{ml})$, or phosphate buffered saline alone as a control. For proliferation studies, RPE cell monolayers were similarly exposed to these agents. The degree of contraction, effects on cell number, and viability were determined up to 14 days after treatment.
\end{abstract}

Results-Contraction of collagen lattices containing RPE cells and proliferation of RPE cells were significantly inhibited $(p<0.05)$ by thiotepa and $5-F U$ at concentrations above $0.06 \mathrm{mg} / \mathrm{ml}$ and $0.25 \mathrm{mg} / \mathrm{ml}$ respectively (for both 5 and 30 minute treatments), compared with controls. Cell death did not occur except for exposure of the RPE cells in collagen lattices to the highest concentration of thiotepa $(4 \mathrm{mg} /$ ml).

Conclusion-It was concluded that single 5 or 30 minute exposures to thiotepa or 5-FU significantly inhibited collagen contraction and the proliferation of RPE cells. These findings suggest that short, single, non-toxic exposures to thiotepa or 5-FU which can be reproduced clinically may be useful in the modulation of proliferative vitreoretinopathy.

(Br f Ophthalmol 1998;82:554-560)

Proliferative vitreoretinopathy (PVR) is the major cause of failure of retinal detachment surgery. ${ }^{1}$ Its pathophysiology involves the proliferation of a variety of cells and the production of extracellular matrix ${ }^{2-4}$ with the formation of epiretinal membranes and their subsequent contraction. There is evidence to suggest that retinal pigment epithelial (RPE) cells play an important part in this process. ${ }^{5-7}$ Recent research has focused on the use of pharmacological agents to prevent the occurrence of PVR. Many drugs have been suggested and used for their specific actions on the various stages of PVR formation but none is used in clinical practice because of the potential for toxicity and the insufficient evidence for the safety of these drugs in human eyes.

Thiotepa (N, N',N" triethylenethiophosphoramide) is a cytostatic, alkylating agent which has been used in the treatment of many tumours. It is non-vesicant and can be given by all parenteral routes as well as directly into the tumour mass. In ophthalmology, it is used both topically as eyedrops in the post-surgical prevention of recurrence of pterygium, and intravitreally for the treatment of retinoblastoma where data on its effect on the retina have been favourable. ${ }^{8}$

5-Fluorouracil (5-FU) is an antiproliferative and an antimetabolite which, after intracellular conversion, acts by interfering with DNA and RNA synthesis. It is increasingly being used as single, short term intraoperative applications to reduce conjunctival scarring after glaucoma surgery. ${ }^{9}$

Blumenkranz et $a l^{10}$ have studied the use of intravitreal 5-FU in an in vivo experimental model of PVR with encouraging results. Although in their study the drug was left inside the eye, Khaw et al ${ }^{11}$ have shown that short exposures to the agent also have long term effects on scleral and subconjunctival fibroblast proliferation both in vitro and in vivo. If effective, the benefits of such single, short term treatments in inhibiting the cellular behaviour which results in PVR, are clear: these drugs can be given as single intraoperative doses and washed away after the treatment period, thus controlling the therapeutic exposure more precisely. Therefore, we have investigated the effects of single 5 and 30 minute exposures to thiotepa or 5-FU on the ability of human RPE cells to contract collagen lattices and to proliferate.

\section{Materials and methods}

CULTURE OF HUMAN RPE CELLS

RPE cells were isolated from human eyes up to 48 hours post mortem using the modified procedure outlined by Edwards. ${ }^{12}$ The cells were cultured in Ham's F10 culture medium containing $20 \%$ (vol/vol) fetal bovine serum, 100 units/ml of penicillin streptomycin (Gibco, Scotland), $3 \mathrm{mg} / \mathrm{ml}$ glucose, and $0.12 \%$ (wt/vol) sodium bicarbonate. Cells between the fourth and fifth passage were used for experimentation.

COLLAGEN MATRIX CONTRACTION STUDY A collagen solution $(5 \mathrm{mg} / \mathrm{ml})$ was prepared using collagen type I (Sigma, Dorset) dissolved in $0.1 \%(\mathrm{vol} / \mathrm{vol})$ glacial acetic acid in sterile
Accepted for publication 27 November 1997 


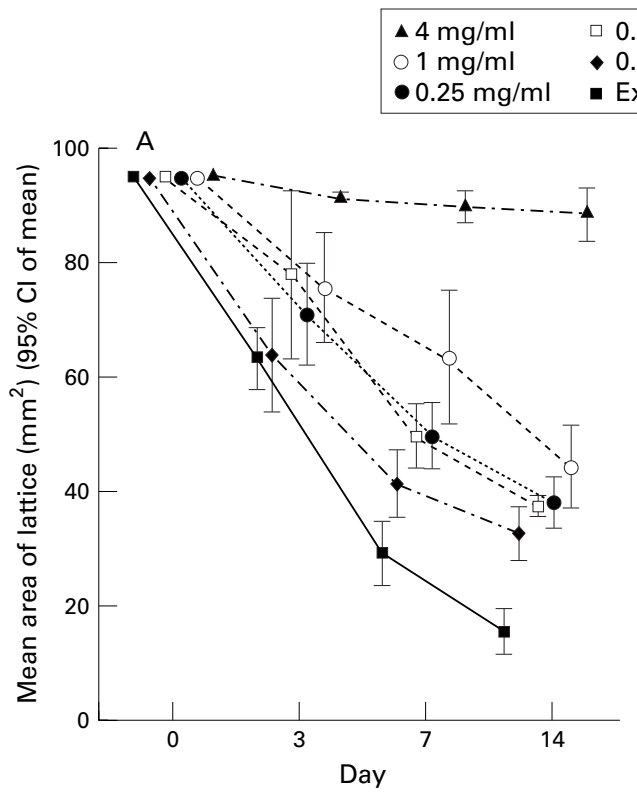

5 minute exposure
$0.12 \mathrm{mg} / \mathrm{ml}$

$0.06 \mathrm{mg} / \mathrm{ml}$

- Exposures to PBS served as controls

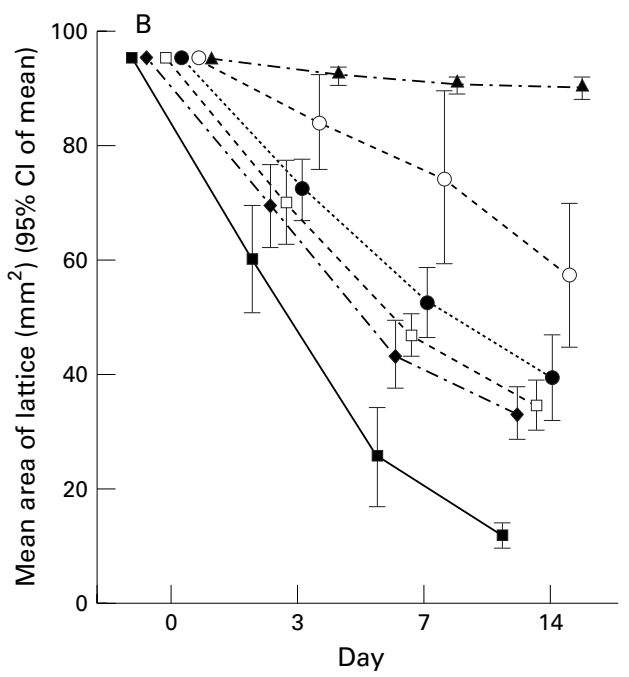

30 minute exposure

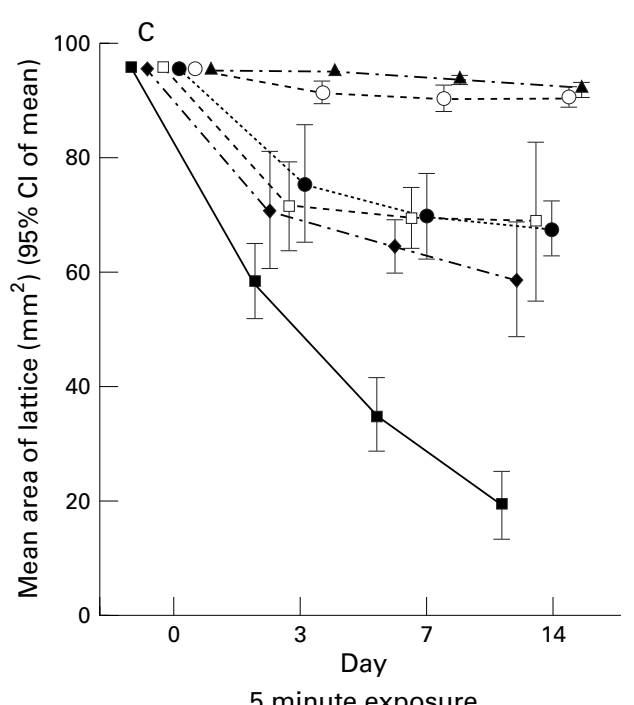

$\square 2.5 \mathrm{mg} / \mathrm{ml}$

- Exposures to PBS served as controls

5 minute exposure

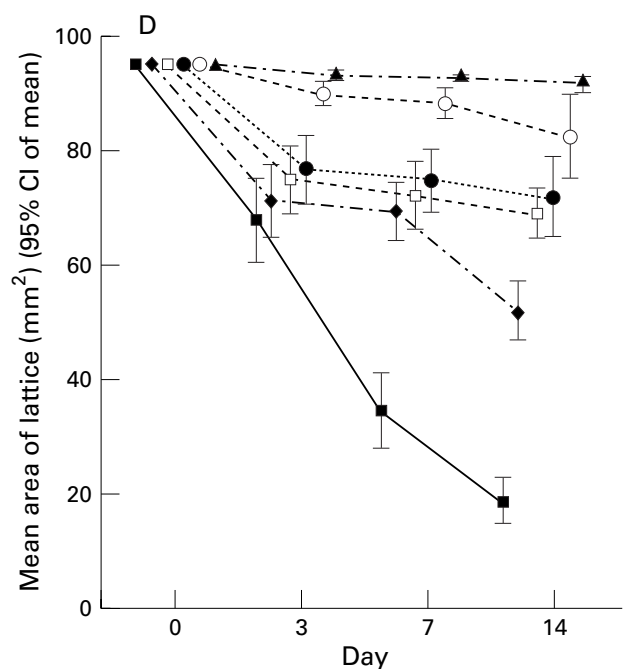

30 minute exposure

Figure 1 Effect of exposure to thiotepa ( $A$ and $B)$ or 5-FU (C and D) on collagen lattice contraction.

distilled water. Using a method that has been previously described, ${ }^{13}$ a collagen lattice mixture containing 400000 human RPE cells $/ \mathrm{ml}$ was prepared. Aliquots $(150 \mu \mathrm{l} /$ well $)$ of the collagen lattice/cell mixture were then added to a 48 well plate and allowed to set at $37^{\circ} \mathrm{C}$ (usually within 2-3 minutes). Once set, $500 \mu \mathrm{l}$ of culture medium were added to each well and the collagen lattice detached from the sides and bottom of the well and allowed to float freely in the culture medium. The collagen lattices were then exposed, in sextuplicate, to thiotepa, 5-FU, or phosphate buffered saline (PBS) (control) for a period of 5 or 30 minutes. The concentrations of thiotepa (Lederle Laboratories, Gosport) used were $4,1,0.25,0.12$, and $0.06 \mathrm{mg} / \mathrm{ml}$, and those of 5-FU (David Bull Laboratories, Warwick) were $25,10,5,2.5$, and $0.25 \mathrm{mg} / \mathrm{ml}$.
The lattices were photographed at days $0,3,7$, and 14 after treatment, and their areas were determined as described previously ${ }^{13}$ using the computer image digitising program (Sigmascan, Jandel Scientific, CA, USA). The results from the sextuplicate wells were expressed as mean area $\left(\mathrm{mm}^{2}\right)$ (with $\left.95 \% \mathrm{CI}\right)$.

PROLIFERATION STUDY

Human RPE cells were seeded into 96 well plates (2000 cells/well). After allowing the cells to settle overnight, the overlying culture medium was aspirated and the monolayers were then exposed, in sextuplicate, to thiotepa, 5-FU, or PBS (control) for a period of 5 or 30 minutes. The wells were then gently washed three times with PBS $(300 \mu 1 /$ well $)$ and fresh culture medium added to each well. The cells 
Table 1 Comparison between the effects of different concentrations of thiotepa and 5-FU on collagen lattice contraction at day 14

\begin{tabular}{|c|c|c|c|c|c|c|c|}
\hline \multirow[b]{2}{*}{ Thiotepa } & & \multicolumn{6}{|c|}{ Concentration of thiotepa $(\mathrm{mg} / \mathrm{ml})$} \\
\hline & & Control & 0.06 & 0.125 & 0.25 & 1.0 & 4.0 \\
\hline \multicolumn{8}{|l|}{ (A) 5 minute exposure to thiotepa: } \\
\hline \multirow[t]{5}{*}{ Concentration of thiotepa $(\mathrm{mg} / \mathrm{ml})$} & 0.06 & 夫 & & & & * & * \\
\hline & 0.125 & * & & & & & * \\
\hline & 0.25 & * & & & & & * \\
\hline & 1.0 & * & & & & & * \\
\hline & 4.0 & * & & & & & \\
\hline \multirow{2}{*}{\multicolumn{8}{|c|}{ (B) 30 minute exposure to thiotepa: }} \\
\hline & 0.06 & * & & & & * & * \\
\hline & 0.125 & $\star$ & & & & $\star$ & * \\
\hline & 0.25 & * & & & & * & $\star$ \\
\hline & 1.0 & * & & & & & * \\
\hline & 4.0 & * & & & & & \\
\hline & & Concentr & of $5-H$ & $m g / m l)$ & & & \\
\hline \multicolumn{2}{|l|}{$5-F U$} & Control & 0.25 & 2.5 & 5.0 & 10.0 & 25.0 \\
\hline \multicolumn{8}{|l|}{ (C) 5 minute exposure to $5-\mathrm{FU}$ : } \\
\hline \multirow[t]{5}{*}{ Concentration of $5-\mathrm{FU}(\mathrm{mg} / \mathrm{ml})$} & 0.25 & * & & & & * & * \\
\hline & 2.5 & * & & & & * & * \\
\hline & 5.0 & * & & & & * & * \\
\hline & 10.0 & * & & & & & \\
\hline \multirow{2}{*}{\multicolumn{8}{|c|}{ (D) 30 minute exposure to $5-\mathrm{FU}$ : }} \\
\hline & & & & & & & \\
\hline \multirow[t]{5}{*}{ Concentration of $5-\mathrm{FU}(\mathrm{mg} / \mathrm{ml})$} & 0.25 & * & & $\star$ & $\star$ & $\star$ & $\star$ \\
\hline & 2.5 & * & & & & * & * \\
\hline & 5.0 & $\star$ & & & & $\star$ & $\star$ \\
\hline & 10.0 & $\star$ & & & & & \\
\hline & 25.0 & $\star$ & & & & & \\
\hline
\end{tabular}

«Denotes significant difference $(\mathrm{p}<0.05)$ between the two concentrations.

were fed every 2 days with a change of culture medium. The concentrations of thiotepa used were the same as those used for the collagen lattice contraction study. The proliferative status of the cells was then analysed by cell count and a colorimetric assay.

On days 0 and 14, a direct cell count was performed. The cell monolayers were gently washed three times with PBS (100 $\mu \mathrm{l} /$ well), then fixed with $100 \%$ methanol and stained with $7 \%$ (vol/vol) Giemsa in distilled water, for 20 minutes. Excess dye was aspirated and the wells washed gently with tap water. Owing to the large number of cells, 10 randomly selected high power fields (magnification $\times 400$ ) were counted on each of the sextuplicate wells. The results were pooled and expressed as a mean percentage of the change in cell numbers (with $95 \%$ CI) from day 0 to day 14 .

Table 2 Percentage change in cell count (with 95\% confidence interval) from day 0 to day 14

\begin{tabular}{|c|c|c|}
\hline & \multicolumn{2}{|l|}{ Thiotepa } \\
\hline & 5 minutes \% change $(95 \% \mathrm{CI})$ & 30 minutes \% change $(95 \% \mathrm{CI})$ \\
\hline \multicolumn{3}{|c|}{ (A) Concentration of thiotepa $(\mathrm{mg} / \mathrm{ml})$ : } \\
\hline Control & $103(87$ to 119$)$ & $83(64$ to 102$)$ \\
\hline 0.06 & $44(31$ to 58$)$ & $42(26$ to 58$)$ \\
\hline 0.12 & $30(9$ to 51$)$ & $11(-3$ to 25$)$ \\
\hline 0.25 & $21(5$ to 36$)$ & $3(-9$ to 16$)$ \\
\hline 1.00 & 24 (8 to 40$)$ & $5(-8$ to 18$)$ \\
\hline \multirow[t]{3}{*}{4.00} & $9(-15$ to 30$)$ & $-9(-15$ to -3$)$ \\
\hline & \multicolumn{2}{|l|}{$5-F U$} \\
\hline & 5 minutes \% change $(95 \% \mathrm{CI})$ & 30 minutes \% change $(95 \% \mathrm{CI})$ \\
\hline \multicolumn{3}{|c|}{ (B) Concentration of $5-\mathrm{FU}(\mathrm{mg} / \mathrm{ml})$ : } \\
\hline Control & $106(83$ to 130$)$ & 74 (52 to 97$)$ \\
\hline 0.06 & $9(0$ to 17$)$ & $6(0$ to 12$)$ \\
\hline 0.12 & $3(-1$ to 8$)$ & $2(-10$ to 14$)$ \\
\hline 0.25 & $-2(-10$ to 6$)$ & $3(-2$ to 8$)$ \\
\hline 1.00 & $-2(-13$ to 8$)$ & $-1(-6$ to 4$)$ \\
\hline 4.00 & $0(-16$ to 17$)$ & $-8(-17$ to 0$)$ \\
\hline
\end{tabular}

See Table 3 (C and D) for significance of results.
The colorimetric assay for cell proliferation (cell proliferation reagent WST-1, Boehringer Mannheim, Lewes) is based on the MTT assay $^{14}$ and measures the activity of the mitochondrial enzyme, succinate tetrazolium reductase, which is directly related to the number of viable cells. The quantification of cell proliferation for each concentration of thiotepa and 5-FU was carried out immediately after treatment (day 0) and on days 3, 7, and 14. Results from the sextuplicate wells were expressed as a mean percentage of proliferation (with $95 \%$ confidence interval (CI)) of the control (control assigned as $100 \%$ proliferation).

\section{CELL VIABILITY}

The viability of cells in monolayer cultures and collagen lattices were determined immediately and 14 days after exposure to thiotepa, 5-FU, or PBS (control) using the trypan blue dye exclusion test. The medium was removed and the cells exposed to $0.04 \%$ (wt/vol) trypan blue in PBS for 5 minutes (for monolayers) and 10 minutes (for collagen lattices). The results from the sextuplicate wells were expressed as a mean percentage of trypan blue positive (nonviable) cells compared with the total cell count. Once the results were obtained, a confirmatory test of previous viability was performed by rendering all cells non-viable (by the addition of $100 \%$ ethanol) and restaining with trypan blue.

\section{STATISTICAL ANALYSIS}

One way analysis of variance (computer software program sPss for Windows Release 6, SPSS Inc, Chicago, USA) was used for analysis of all results. Multiple comparisons between the effects of various concentrations and controls 
Table 3 Comparison between the effects of different concentrations of thiotepa and 5-FU on cell proliferation (cell count) at day 14

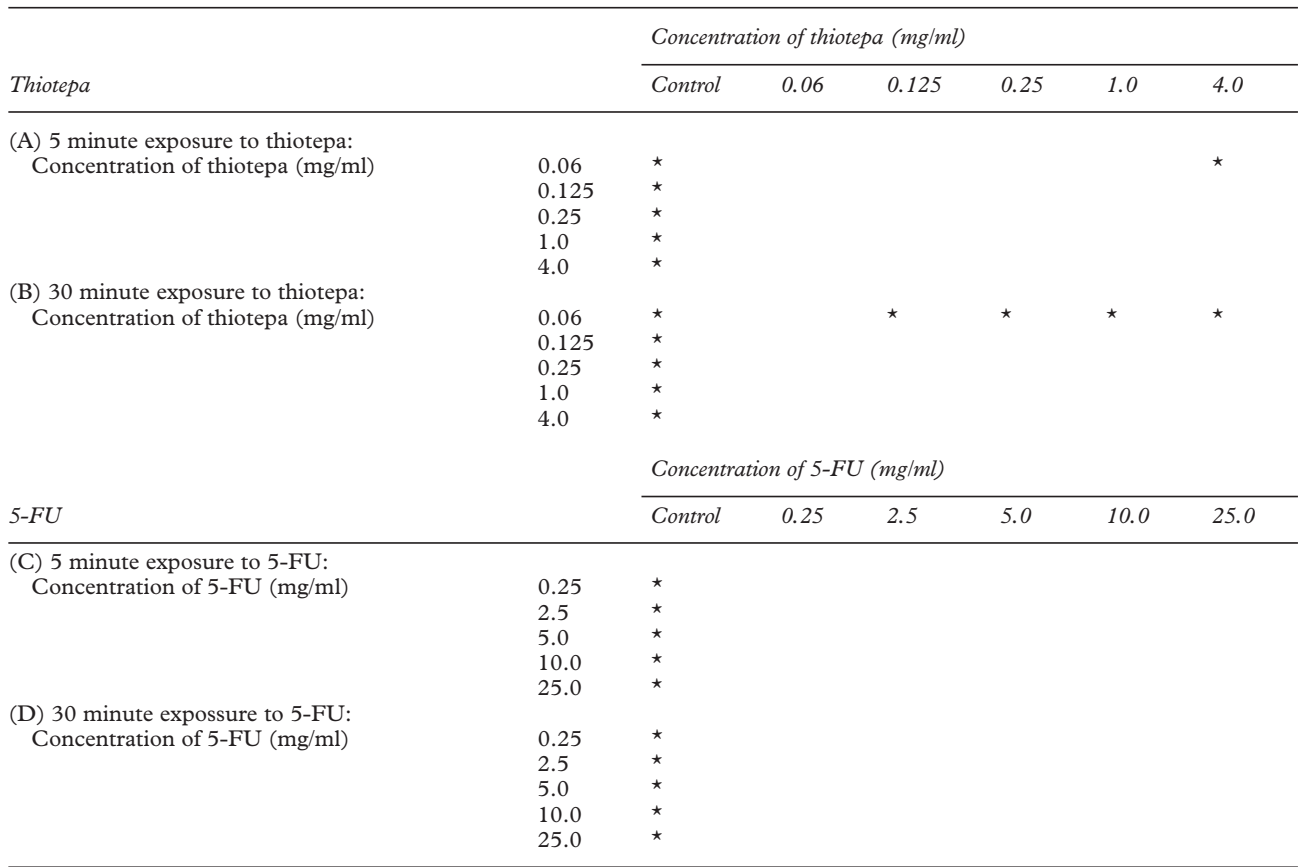

^Denotes significant difference $(\mathrm{p}<0.05)$ between the two concentrations.

were made and the observed significance levels were adjusted using the Bonferroni test.

\section{Results}

EFFECTS OF THIOTEPA AND 5-FU ON COLLAGEN LATTICE CONTRACTION

At all concentrations of thiotepa and 5-FU (5 and 30 minute exposures), the lattices contracted significantly less than their respective controls $(\mathrm{p}<0.05)$ for up to 14 days after treatment (Fig 1). The degree of inhibition of contraction appeared to be concentration depend- ent for both thiotepa and 5-FU. Table 1 (A-D) shows the statistically significant differences in effect (if any) between any two concentrations. The asterisk represents statistically significant $(\mathrm{p}<0.05)$ differences.

EFFECTS OF THIOTEPA AND 5-FU ON RPE CELI PROLIFERATION

Exposure to either thiotepa or 5-FU ( 5 and 30 minutes) significantly inhibited $(\mathrm{p}<0.05)$ an increase in counted cell number up to 14 days after treatment compared with controls (Table

Table 4 Comparison between the effects of different concentrations of thiotepa and 5-FU on cell proliferation (colorimetric test) at day 14

\begin{tabular}{|c|c|c|c|c|c|c|c|}
\hline \multirow[b]{2}{*}{ Thiotepa } & & \multicolumn{6}{|c|}{ Concentration of thiotepa $(\mathrm{mg} / \mathrm{ml})$} \\
\hline & & Control & 0.06 & 0.125 & 0.25 & 1.0 & 4.0 \\
\hline \multicolumn{8}{|l|}{ (A) 5 minute exposure to thiotepa: } \\
\hline \multirow[t]{5}{*}{ Concentration of thiotepa $(\mathrm{mg} / \mathrm{ml})$} & 0.06 & * & & $\star$ & * & * & * \\
\hline & 0.125 & $\star$ & & & & & $\star$ \\
\hline & 0.25 & $\star$ & & & & & $\star$ \\
\hline & 1.0 & $\star$ & & & & & * \\
\hline & 4.0 & $\star$ & & & & & \\
\hline \multicolumn{8}{|l|}{ (B) 30 minute exposure to thiotepa: } \\
\hline \multirow[t]{6}{*}{ Concentration of thiotepa $(\mathrm{mg} / \mathrm{ml})$} & 0.06 & * & & & & & * \\
\hline & 0.125 & $\star$ & & & & & $\star$ \\
\hline & 0.25 & * & & & & & $\star$ \\
\hline & 1.0 & * & & & & & * \\
\hline & 4.0 & * & & & & & \\
\hline & & \multicolumn{6}{|c|}{ Concentration of 5-FU $(\mathrm{mg} / \mathrm{ml})$} \\
\hline $5-F U$ & & Control & 0.25 & 2.5 & 5.0 & 10.0 & 25.0 \\
\hline \multicolumn{8}{|l|}{ (C) 5 minute exposure to $5-\mathrm{FU}:$} \\
\hline \multirow[t]{5}{*}{ Concentration of $5-\mathrm{FU}(\mathrm{mg} / \mathrm{ml})$} & 0.25 & $\star$ & & & & & \\
\hline & 2.5 & * & & & & & \\
\hline & 5.0 & $\star$ & & & & & \\
\hline & 10.0 & $\star$ & & & & & \\
\hline & 25.0 & * & & & & & \\
\hline \multicolumn{8}{|l|}{ (D) 30 minute exposure to $5-\mathrm{FU}$ : } \\
\hline \multirow[t]{5}{*}{ Concentration of $5-\mathrm{FU}(\mathrm{mg} / \mathrm{ml})$} & 0.25 & * & & & & & \\
\hline & 2.5 & * & & & & & \\
\hline & 5.0 & * & & & & & \\
\hline & 10.0 & * & & & & & \\
\hline & 25.0 & * & & & & & \\
\hline
\end{tabular}

*Denotes significant difference $(\mathrm{p}<0.05)$ between the two concentrations. 


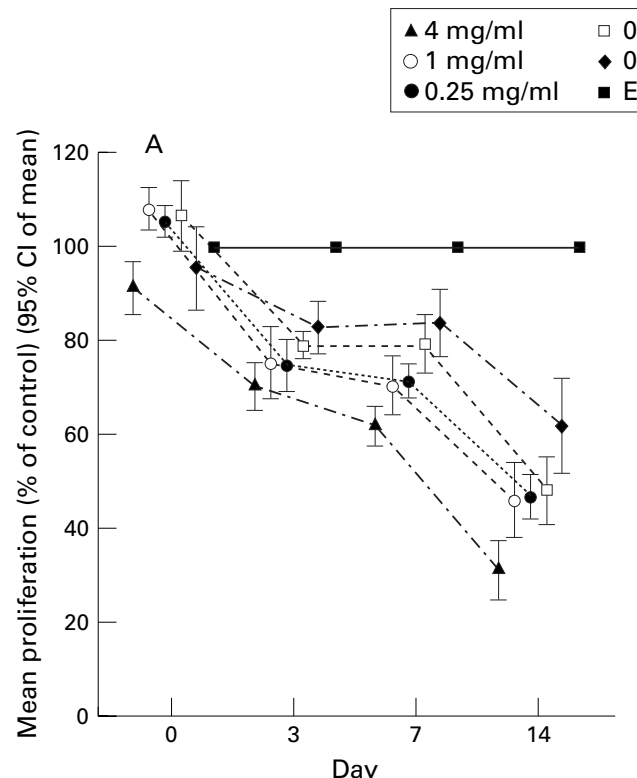

5 minute exposure
$0.12 \mathrm{mg} / \mathrm{ml}$

$0.06 \mathrm{mg} / \mathrm{ml}$

- Exposures to PBS served as controls

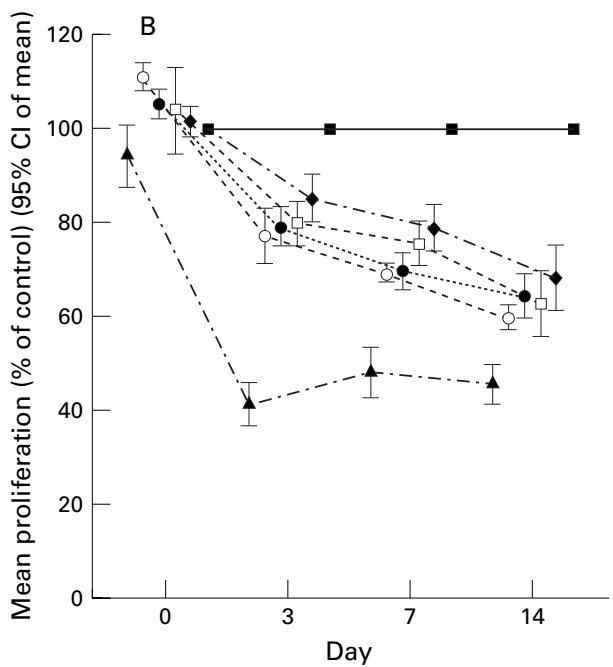

30 minute exposure

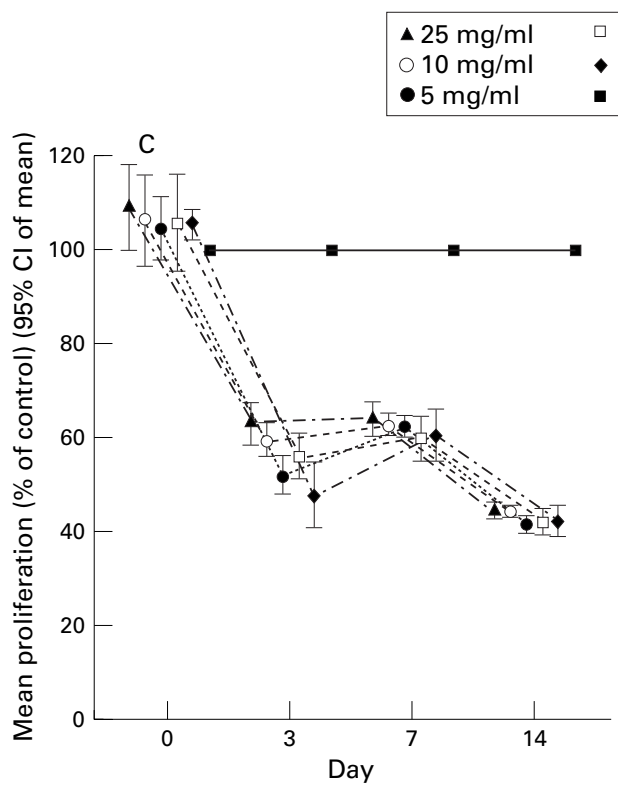

5 minute exposure $\square 2.5 \mathrm{mg} / \mathrm{ml}$

- $0.25 \mathrm{mg} / \mathrm{ml}$

- Exposures to PBS served as controls

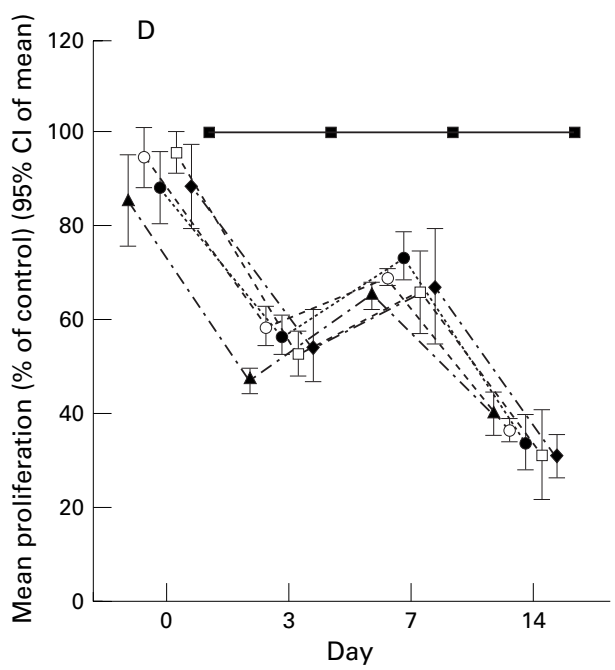

30 minute exposure

Figure 2 Effect of exposure to thiotepa ( $A$ and B) or 5-FU (C and D) on RPE cell proliferation (using a colorimetric test).

$2 \mathrm{~A}$ and $2 \mathrm{~B})$. Similar results were obtained using the WST cell proliferation assay (Fig 2) with both thiotepa and 5-FU significantly inhibiting RPE cell proliferation at 5 and 30 minute exposures. Although the inhibitory effects of both drugs appeared to be concentration dependent, this was more marked with thiotepa. Tables $3(\mathrm{~A}-\mathrm{D})$ and $4(\mathrm{~A}-\mathrm{D})$ show the statistically significant differences in effect (if any) between concentrations.

EFFECTS OF THIOTEPA AND 5-FU ON CELL VIABILITY IN MONOLAYER CULTURES AND IN COLLAGEN LATTICES

Immediately after treatment there were no trypan blue positive cells (non-viable) in the monolayers or collagen lattices for all concentrations of 5-FU and thiotepa (5 and 30 minute exposures) tested (data not shown). At day 14 , in the monolayers, there were no nonviable cells for all concentrations of 5-FU and thiotepa ( 5 and 30 minute exposures). In collagen lattices there were no non-viable cells for all concentrations of 5-FU and for thiotepa up to $1 \mathrm{mg} / \mathrm{ml}$ ( 5 and 30 minute exposures). However, at the highest concentration of thiotepa $(4 \mathrm{mg} / \mathrm{ml})$, the percentage of nonviable cells in collagen gels were $70 \%$ and $90 \%$ for 5 minute and 30 minute exposures respectively.

\section{Discussion}

Based on current data and understanding, chemotherapy for the prevention and treatment of PVR is not routinely used for a number of reasons including the intravitreal access required, the potential need for repeated subconjunctival instillations with its associated 
corneal problems and fear of retinal toxicity from long term drug exposure. In this study, two in vitro models simulating the main processes in PVR were used to study the effects of single 5 or 30 minute exposure of human $\mathrm{RPE}$ cells to thiotepa or 5-FU. The first model looked at the effects of the drugs on the contraction of collagen lattice containing RPE cells; the second studied the effects on proliferation of RPE cell monolayers.

Although somewhat simplistic, the three dimensional collagen matrix used in this study has many similarities to in vivo PVR membranes. These include the presence of blood products and stimulatory and inhibitory factors secreted by inflammatory and other cells. As with any model, differences also exist. In PVR membranes, for example, there are many cell types other than RPE cells and a variety of collagen types not only type I. Nevertheless, we felt that this model was sufficiently representative of in vivo PVR and therefore of value in assessing the effects of the drugs, at least in the initial stages.

The use of cell monolayers to study the effect of drugs on cell proliferation has been described in many studies. ${ }^{15} 16$ In most cases, direct cell count has been used to assess the effects of the treatments investigated. In addition to the cell count method, we also used a commercially available indirect cell proliferation assay (WST cell proliferation assay). The latter estimates the metabolic activity (activity of a mitochondrial enzyme, succinate tetrazolium) and assumes that it is directly related to the degree of cell proliferation.

The use of single, short term treatments of 5-FU to reduce conjunctival scarring posttrabeculectomy is well established, ${ }^{9}$ but for reasons discussed above, its intraocular use is still not routinely practised. Blumenkranz et al ${ }^{10}$ studied the effect of fluorouracil using an in vivo experimental model of PVR and found the use of single intravitreal injections of $1 \mathrm{mg}$ of 5-FU alone, with indomethacin or followed by seven daily subconjunctival injections of $10 \mathrm{mg}$ to be effective. In their study, the drugs were instilled and left in situ thereby allowing prolonged exposures. Occleston et al ${ }^{13}$ studied the effects of single 5 minute exposures of 5 -FU and mitomycin on ocular fibroblast mediated collagen contraction. They found both drugs were effective in inhibiting lattice contraction although mitomycin had significant effects on cell viability. In this study we also chose to use 5-FU because although its metabolite, 5-fluorouridine has been shown to be nearly 100 times more effective as an inhibitor of human retinal epithelial cell proliferation, ${ }^{17}$ its clinical use is not as well established as 5-FU. To determine doses of the drug to be used in this study, a pilot study was conducted using a wide range of concentrations. This showed that although low doses of 5-FU were effective in preventing the proliferation of cells they did not inhibit lattice contraction to any significant degree. These findings were in agreement with those of Hartzer et al ${ }^{18}$ who found that 48 hours of exposure to 5-FU at a dose of $200 \mu \mathrm{g} / \mathrm{ml}$ had virtually no effect on the cell mediated contrac- tion of either human dermal or scleral fibroblasts. We felt that the collagen lattice model is more akin to PVR in vivo and the effects of antimetabolites on collagen lattice contraction would have greater clinical implications compared with its effects on cell proliferation. For this reason and because exposure time was limited to only 5 or 30 minutes followed by removal of the drug, a range of concentrations based on the contraction model was chosen with a minimum dose of $250 \mu \mathrm{g} / \mathrm{ml}$ of $5-\mathrm{FU}$ although these represent higher doses than those used in Blumenkranz's study.

In ophthalmology, the main use of thiotepa is for the prevention of the recurrence of pterygium after surgical removal ${ }^{19}$ where it is given as eyedrops, a $0.05 \%$ solution instilled every 3 hours while awake for up to 8 weeks without significant toxicity to the cornea or conjunctiva. ${ }^{19}$ Thiotepa is also used intravitreally for the treatment of recurrent retinoblastoma. ${ }^{80}$ Early findings $^{2021}$ and work by Seregard et $a l^{8}$ using thiotepa (repeated injections of $2 \mathrm{mg}$ in $0.5 \mathrm{ml}$ into the vitreous) for the treatment of retinoblastoma also suggest that thiotepa causes tumour cell death with no significant retinal toxicity despite the use of up to five repeated intravitreal injections. Barrada et $a l^{22}$ used monkey eyes to test the toxicity of a combination of thiotepa $(8 \mu \mathrm{g} / \mathrm{ml})$, 5 -FU $(250 \mu \mathrm{g} / \mathrm{ml})$, and etoposide $(40 \mu \mathrm{g} / \mathrm{ml})$ in the vitrectomy infusion fluid. Using clinical, electrophysiological, and histological criteria they did not find any apparent toxicity to the retina. It is based on the above data that the doses of thiotepa used were chosen.

This study has shown that in the monolayer RPE cell model, proliferation was inhibited by both thiotepa (in a dose dependent manner) and 5-FU (minimal dose dependency) without cell death. In the collagen lattice model, the viability of the cells was also not reduced except for the highest concentration $(4 \mathrm{mg} / \mathrm{ml})$ of thiotepa. At this concentration, exposures of 5 and 30 minutes caused cell death. It is possible that some drug may have been retained in the lattice despite washing with PBS after the exposure time, resulting in prolonged drug exposure and toxicity compared with the monolayer cultures. However, as the degree of inhibition of contraction is dose dependent, lower doses may be sufficient to achieve the required effects. Of interest is the comparable degree of inhibition of proliferation and lattice contraction with 5 and 30 minute exposures. This may be because intracellular accumulation of the drug is rapid and reaches a saturation point within 5 minutes. Further drug exposure in this situation would not have much greater effect. It has been found that in one tumour cell line, maximal intracellular accumulation of 5-FU occurs within 200 seconds. ${ }^{23}$ If this effect is reproducible in vivo, the benefit of 5 minute treatments would be twofold. Firstly, exposure of the retina to the drug would be minimised, thereby reducing the risk of toxicity. Secondly, to achieve 30 minute exposures, continuous irrigation of the drug during the operation would be required with the associated risk of increased exposure of the surgeon to the drug. 
Five minute exposures, however, could be achieved by instillation and removal of the drug, thereby reducing such a risk.

We conclude that, depending upon the concentration of agent used, single, short term exposures to thiotepa or 5-FU are effective in inhibiting the proliferation of RPE cells and contraction of collagen lattices without killing the cells. In clinical practice, the use of short term single exposures is possible with minimal additional risk in cases where intraocular access is already available. A vitrectomy operation for retinal detachment and a continuous infusion is one such situation which provides an opportunity for the use of short term, one off intravitreal applications of drugs. This would increase the control over the therapeutic exposure and is likely to reduce the incidence of toxicity to the surrounding photoreceptors in vivo. Further in vivo studies are planned to determine the optimum concentration of drug that would be effective in the prevention of postoperative PVR.

This research was supported by the June Sutor Research Fellowship, Moorfields Trustees, and the International Glaucoma Association.

1 The Retina Society Terminology Committee. The classification of retinal detachment with proliferative vitreo-
retinopathy. Ophthalmology 1983;90:121-5.

2 Jerdan JA, Pepose JS, Michels RG, et al. Proliferative vitreoretinopathy membranes. An immunohistochemical study. Ophthalmology 1989;96:801-10.

3 Morino I, Hiscott P, McKechnie N, et al. Variation in epiretinal membrane components with clinical duration of the proliferative tissue. Br 7 Ophthalmol 1990;74:393-9.

4 Scheiffarth OF, Kampik A, Gunther H, et al. Proteins of the extracellular matrix in vitreoretinal membranes. Graefes Arch Clin Exp Ophthalmol 1988;226:357-61.

5 Mandelcorn MS, Machemer R, Fineberg E, et al. Proliferation and metaplasia of intravitreal retinal pigment epithelium cell autotransplants. Am F Ophthalmol 1975;80:22737 .

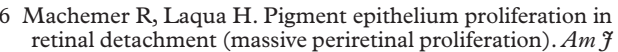
retinal detachment (massive
Ophthalmol 1975;80:1-23.

7 Hiscott PS, Grierson I, McLeod D. Retinal pigment epithelial cells in epiretinal membranes: an immunohistochemical study. Br F Ophthalmol 1984;68:708-15.

8 Seregard S, Kock E, af Trampe E. Intravitreal chemotherapy for recurrent retinoblasto

9 Khaw PT, Migdal CS. Current techniques in wound healing modulation in glaucoma surgery. Curr Opin Ophthalmol 1996;7:24-33.

10 Blumenkranz MS, Ophir A, Claflin AJ, et al. Fluorouracil for the treatment of massive periretinal proliferation. Am $\mathcal{F}$ Ophthalmol 1982;94:458-67.

11 Khaw PT, Doyle JW, Sherwood MB, et al. Prolonged localized tissue effects from 5-minute exposures to fluorouracil and mitomycin C. Arch Ophthalmol 1993;111:263-7.

12 Edwards RB. Culture of mammalian retinal pigment epithelium and neural retina. Methods Enzymol 1982;81:39-43.

13 Occleston NL, Alexander RA, Mazure A, et al. Effects of single exposures to antiproliferative agents on ocular single exposures to antiproliferative agents on ocular
fibroblast-mediated collagen contraction. Invest Ophthalmol Vis Sci 1994;35:3681-90.

14 Mosmann T. Rapid colorimetric assay for cellular growth and survival: application to proliferation and cytotoxicity assays. F Immunolol Methods 1983;65:55-63.

15 Khaw PT, Ward S, Porter A, et al. The long-term effects of 5 -fluorouracil and sodium butyrate on human Tenon's fibroblasts. Invest Ophthalmol Vis Sci 1992;33:2043-52.

16 Khaw PT, Ward S, Grierson I, et al. Effect of beta radiation on proliferating human Tenon's capsule fibroblasts. $\mathrm{Br} \mathcal{F}$ Ophthalmol 1991;75:580-3.

17 Blumenkranz MS, Hartzer MK, Hajek AS. Selection of therapeutic agents for intraocular proliferative disease. II Differing antiproliferative activity of the fluoropyrimidines. Arch Ophthalmol 1987;105:396-9.

18 Hartzer MK, Blumenkranz MS, Hajek AS, et al. Selection of therapeutic agents for intraocular proliferative disease. 3 Effects of fluoropyrimidines on cell-mediated contraction of human fibroblasts. Exp Eye Res 1989;48:321-8.

19 Ehrlich D. The management of pterygium. Ophthalmic Surg 1977;8:23-30.

20 Ericson LA, Rosengren BHO. Present therapeutic resources in retinoblastoma. Acta Ophthalmol 1961;39:569-76.

21 Ericson L, Karlberg B, Rosengren BH. Trials of intravitreal injections of chemotherapeutic agents in rabbits. Acta Ophthalmol 1964;42:721-6.

22 Barrada A, Peyman GA, Case J, et al. Evaluation of intravitreal 5-fluorouracil, vincristine, VP 16, doxorubicin, and thiotepa in primate eyes. Ophthalmic Surg 1984;15:767-9.

23 Wohlhueter RM, Melvor RS, Plagemann PGW. Facilitated transport of uracil and 5-fluorouracil, and permeation of orotic acid into cultured mammalian cells. 7 Cell Physiol 1980;104:209-19. 